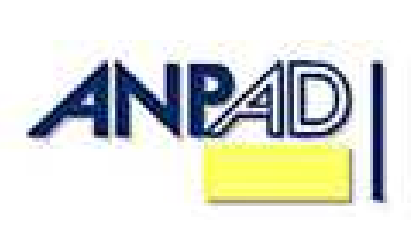

Disponível em

http://www.anpad.org.br/rac

RAC, Rio de Janeiro, v. 16, n. 6, art. 6, pp. 866-888, Nov./Dez. 2012

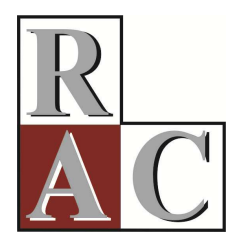

\title{
Internacionalização Acelerada de Empresas de Base Tecnológica: o Caso das Born Globals Brasileiras
}

Accelerated Internationalization of Technology-based firms: the Case of Brazilian BornGlobals

Fernanda Ferreira Ribeiro *

E-mail: fribeiro@pucsp.br

Pontifícia Universidade Católica de São Paulo - PUC-SP

São Paulo, SP, Brasil.

Moacir Miranda Oliveira Jr. E-mail: mirandaoliveira@usp.br Universidade de São Paulo - FEA/USP

São Paulo, SP, Brasil.

Felipe Mendes Borini E-mail: fborini@espm.br Escola Superior de Propaganda e Marketing - ESPM

São Paulo, SP, Brasil.

* Endereço: Fernanda Ferreira Ribeiro Rua Monte Alegre, 984, Sala 133 ${ }^{\mathrm{a}} 1^{\mathrm{o}}$ andar, Edifício Reitor Bandeira de Mello Perdizes, São Paulo/SP, 05014001. 


\title{
Resumo
}

O fenômeno born global tem sido relatado, principalmente em setores de alta tecnologia, e tem requerido novos entendimentos teóricos sobre a atuação internacional de empresas nascentes e pequenas. Este artigo analisa a relação dos fatores do ambiente externo da empresa no país de origem, fatores organizacionais e fatores do empreendedor pelos quais algumas empresas de base tecnológica (EBTs) se internacionalizam de maneira acelerada. Um survey foi aplicado a EBTs brasileiras. Ao final da coleta de dados, a primeira base de dados gerada continha 214 respostas, das quais 85 foram obtidas de empresas com algum tipo de negócio no exterior, 39,7\%. Destes, 54 questionários foram considerados válidos para esta pesquisa. Os dados foram analisados utilizando-se técnicas estatísticas de regressão logística. Os resultados mostram que os fatores externos à empresa influenciam mais na internacionalização das EBTs em relação aos fatores internos. A integração em cadeias produtivas globais e as habilidades gerenciais internacionais do empreendedor aparecem como os fatores que melhor discriminam a internacionalização das EBTs born globals. Portanto, esta pesquisa contribui para a discussão do processo de internacionalização acelerada das EBTs, contribuindo para suprir a lacuna da importância dos fatores externos, internos e do empreendedor no processo de internacionalização dessas empresas.

Palavra-chaves: internacionalização; born globals; empresa de base tecnológica.

\begin{abstract}
The born global phenomenon has been made apparent, mainly in high technology sectors, which requires new theoretical understandings about the role of nascent and small international companies. This article analyzes the relationship between a company's external environment in its country of origin, internal organizational factors and the factors relating to how some technology-based firms (TBFs) internationalize. A survey was applied to Brazilian TBFs. At the end of the data collection period, the first database generated 214 responses. Out of these, $85(39.7 \%)$ were obtained from companies involved in some kind of business abroad. However, only 54 questionnaires were considered valid for this research. The data were analyzed using logistic regression statistical techniques. The results show that external factors influence the internationalization of TBFs more as compared to internal factors. Integration in the value chain and an entrepreneur's ability to manage internationally are the factors that best distinguish the internationalization of born-global TBFs. Thus, this paper contributes to the discussion of the internationalization process of born-globals and TBFs, filling the gap regarding the importance of external, internal and entrepreneurial factors in these companies' internationalization processes.
\end{abstract}

Key words: internationalization; born-globals; technology-based firms. 


\section{Introdução}

Até o final da década de 1980, os principais exemplos de empresas multinacionais consistiam de corporações maduras, com grande poder de mercado e oriundas de economias desenvolvidas. Nos últimos vinte anos, os negócios internacionais têm-se modificado. Este artigo aborda um fenômeno que evidencia uma das mudanças que estão ocorrendo nos negócios internacionais: o recente aparecimento de empresas de base tecnológica (EBTs) que se internacionalizam de maneira acelerada desde sua fundação ou poucos anos após sua fundação.

Na última década, os estudos mostraram EBTs que vêm obtendo sucesso competitivo em seus negócios no exterior, principalmente quando essas empresas possuem produtos de alto conteúdo tecnológico e capacidade de inovação (Knight \& Cavusgil, 2004; Knight \& Kim, 2009; Oviatt \& McDougall, 1994). O fenômeno born global, assim como é chamado, não é restrito a empresas de setores de base tecnológica, porém é mais recorrente e mais analisado nesses setores (Dominguinhos \& Simões, 2001; Rialp, Rialp, \& Knight, 2005).

Os estudos apontam que tais empresas estão aparecendo em grande número e em diferentes regiões do mundo, caracterizando "novas espécies de negócios internacionais" que parecem se comportar de maneira diferente das multinacionais tradicionais (Mathews \& Zander, 2007, p. 390). No que se refere à realidade brasileira, o fenômeno também tem ocorrido. Todavia, quando se trata de empresas de base tecnológica, os exemplos de internacionalização acelerada, e até mesmo de algum tipo de internacionalização, são raros.

Ademais, as teorias tradicionais de internacionalização têm limitações para explicar o fenômeno, o que instiga os pesquisadores a tentar entender os recursos e as competências internas que levam uma empresa a ser born global (Knight \& Kim, 2009; Sperling, 2005), explorar questões ligadas ao empreendedor desse tipo de empresa (Andersson, 2000; Oviatt \& McDougall, 1994; Simões \& Dominguinhos, 2001) e a articulação da empresa com seu ambiente externo, principalmente com o ambiente de negócio do país de origem (Fernhaber, Gilbert, \& McDougall, 2008).

Nos estudos internacionais sobre born globals, os fatores internos da firma e os ligados ao empreendedor são mais recorrentes; no entanto, os estudos foram empreendidos em sua maioria em países desenvolvidos com uma realidade de tecnologia e inovação distinta da realidade brasileira (Fernhaber et al., 2008; Knight \& Kim, 2009). Além disso, as revisões mais recentes apontam uma lacuna de estudos no entendimento do papel de fatores externos como o do ambiente de origem e a localização da empresa no fenômeno born global. Fernhaber Gilbert e McDougall (2003) e Fernhaber Gilbert e McDougall (2008) apontam que essa lacuna é até surpreendente, primeiro em virtude do crescimento de áreas nos EUA como o Silicon Valley e o Research Triangle e, segundo, em decorrência do aparecimento e do crescimento de áreas similares em vários países do mundo. Logo, sabe-se muito pouco sobre o que os executivos das EBTs pensam ou utilizam das políticas recentes de apoio externo e de promoção de exportações sobre a internacionalização acelerada de EBTs de países em desenvolvimento, tal como o Brasil.

Mediante esse panorama, o objetivo do artigo é analisar como a internacionalização acelerada de EBTs está associada aos fatores do ambiente externo da empresa no país de origem, aos fatores internos da organização e aos fatores ligados ao empreendedor.

Com relação à sua estrutura, este artigo é composto por seis partes, além desta introdução. A próxima apresenta um referencial teórico com relação ao conceito e às características das empresas born globals, e são também apresentadas as características dos fatores e a forma como eles podem influenciar a internacionalização dessas empresas. Em seguida, apresentam-se as hipóteses do estudo. Na parte quatro, são discutidos os aspectos metodológicos. Por fim, são abordados os resultados e apresentadas as conclusões gerais do estudo. 


\section{Referencial Teórico}

\section{A empresa born global a a empresa de base tecnológica}

Os estudos sobre o fenômeno born global são relativamente recentes e datam pouco mais de uma década (Knight \& Cavusgil, 2004; Knight \& Kim, 2009; Oviatt \& McDougall, 1994; Rialp et al., 2005). As born globals são apresentadas como empresas que estabelecem atividades no exterior desde a sua fundação ou poucos anos após sua criação. São empresas que podem assumir negócios no mercado internacional simultaneamente ao estabelecimento de negócios no mercado doméstico, ou às vezes, sem nenhuma experiência ou com pouco tempo de operação no próprio mercado interno.

Mais de uma década depois do trabalho pioneiro de Oviatt e McDougall (1994), muito se discutiu sobre o fenômeno, mas não há ainda definições gerais sobre o conceito. Na literatura, as diferentes denominações das empresas com internacionalização acelerada mostram-se como variações do mesmo fenômeno (Rialp et al., 2005), tais como international new ventures (Oviatt \& McDougall, 1994), born globals (Knight \& Cavusgil, 1996), global start-ups (Madsen \& Servais, 1997; Oviatt \& McDougall, 1995), global high-tech firms (Roberts \& Senturia, 1996), entre outras denominações.

Apesar do razoável consenso teórico do que é uma born global, o mesmo não pode ser concluído sobre a operacionalização empírica desse conceito (Dib, Rocha, \& Silva, 2010). Ainda há muita controvérsia, diferentes critérios têm sido escolhidos pelos autores, tornando assim qualquer intenção de comparação extremamente desafiadora. Os critérios mais recorrentes (Dib et al., 2010; Rialp et al., 2005) são: data de fundação (a maioria dos autores considera que as empresas born globals surgiram depois de 1990); início das atividades internacionais depois da fundação (varia de 02 até 15 anos); percentagem do faturamento proveniente de operações no exterior (varia de 5\% até 75\%, para firmas com pequenos mercados domésticos); abrangência de mercados (um ou poucos mercados internacionais, na mesma ou em várias regiões do mundo). Uma observação dessas variáveis sugere que a adoção de uma definição é contingente do tipo de país de origem da empresa e das características de seu ambiente de negócios (Dib et al., 2010; Dib \& Rocha, 2008).

Dominguinhos e Simões (2001) frisam que esse tipo de empresa é mais comum em indústrias de alta tecnologia, como softwares, eletrônicos, biotecnologia, aeroespacial e instrumentos médicos, porém não são restritas a estes setores. Os próprios autores apresentam o caso de uma empresa born global da indústria calçadista de Portugal. No entanto, o foco deste trabalho está alinhado com os estudos mais proeminentes da área, que se atêm à internacionalização acelerada de setores de maior densidade tecnológica, e assim aqui são estudadas as empresas brasileiras de base tecnológica (EBTs). As EBTs são definidas como pequenas e médias empresas de setores de alta tecnologia que realizam esforços tecnológicos significativos e concentram suas operações na fabricação de novos produtos (Pinho, 2005).

As EBTs são caracterizadas por esforço tecnológico expressivo, mas, no contexto de pequenas e médias empresas de países em desenvolvimento, tal iniciativa pode ser realizada em outros formatos que não o de $\mathrm{P} \& \mathrm{D}$ agregado à estrutura da empresa. Dessa forma, o conceito de EBT não deve se restringir aos critérios clássicos de intensidade em $\mathrm{P} \& \mathrm{D}$, mas cobrir também arranjos menos formalizados e a articulação direta com instituições de pesquisa e universidades. O predomínio do P\&D não estruturado tem relação com o pequeno porte da maioria das EBTs (Pinho, 2005).

Em termos de atuação internacional, uma característica das EBTs de economias emergentes é o fato de que suas estratégias tecnológicas e de mercado serem, na grande maioria dos casos, pautadas pela imitação, o que leva a dificuldades para criarem seus mercados e esbarrarem com concorrentes externos mais estruturados e de maior porte que fornecem, nos mercados estrangeiros, o mesmo produto ou produto similar (Furman \& Hyves, 2004; Govindarajan \& Ramamurti, 2011). Além disso, de maneira geral, as EBTs se reconhecem como empresas que atuam em nichos de mercado, tanto em seu mercado nacional como no mercado internacional (Rialp et al., 2005). 
No caso das EBTs brasileiras, as oportunidades para a operação de EBTs dão-se principalmente em mercados nos quais a demanda brasileira é pequena demais para justificar a internalização da operação dos concorrentes estrangeiros. Ou, ainda, em mercados que, mesmo nos países desenvolvidos, não apresentam interesse de uma extensão suficiente para atuação de empresas mais estruturadas. Nesses nichos, há um potencial de sucesso para as EBTs brasileiras (Pinho, 2005).

\section{Fatores relevantes na internacionalização acelerada}

Os modelos de born globals podem ser divididos em: (a) modelos que tentam explicar a emergência e as características das born globals a partir do início dos anos 90; (b) modelos que sugiram no final dos anos 90 derivados de estudos que tinham por preocupação entender como o fenômeno born global desafiava as teorias internacionais; e (c) estudos mais recentes, que partem do princípio de que as teorias tradicionais de internacionalização são limitadas para entender as born globals e procuram identificar e compreender os fatores de internacionalização acelerada (Almor, 2000).

Dentre os estudos mais recentes, vários, como o de Zahra e George (2002); Mathews e Zander (2007); Dominguinhos e Simões (2001); Dib, Rocha e Silva (2010); Oviatt e McDougall (1994); Knight e Kim (2009); Gabrielsson, Kirpalani, Dimitratos, Solberg e Zucchellag (2008); entre outros, elaboraram abordagens teóricas a partir da identificação e da análise de fatores internos e externos à empresa que pudessem explicar o que a levaria a ser capaz de entrar no exterior desde sua fundação ou poucos anos depois dela. No entanto, Madsen e Servais (1997), Zahra e George (2002) e Dib et al. (2010) apontam para o fato de que a maioria dos autores que conduzem pesquisas empíricas sobre as born globals elaboram uma lista própria de fatores de atuação dessas empresas no exterior.

Nos estudos sobre born globals, os fatores internos da firma e os fatores ligados aos empreendedor são mais recorrentes. Os trabalhos que fazem análise do ambiente externo dessas empresas são mais raros (Fernhaber et al., 2008, Zahra \& George, 2002). Zahra e George (2002) atribuem essa lacuna de estudos à complexidade e à variedade de combinações possíveis de fatores externos que poderiam ter alguma influência.

Com base na literatura internacional foi elaborada, no presente estudo, uma lista de fatores do ambiente externo do país de origem (ambientais), fatores internos da organização (organizacionais) e fatores ligados ao empreendedor. Assim, o modelo proposto concentrou-se na articulação da empresa com seu ambiente externo, relacionado ao ambiente de negócio do país de origem (Fernhaber et al., 2008), nos fatores organizacionais que levam uma empresa a ser born global (Knight \& Kim, 2009; Sperling, 2005), e também nas questões ligadas ao empreendedor desse tipo de empresa (Andersson, 2000; Oviatt \& McDougall, 1994; Simões \& Dominguinhos, 2001).

\section{Hipóteses da Pesquisa}

\section{Fatores externos}

Para uma EBT born global (iniciante e pequena), o país de origem pode ter uma importância maior para sua atuação internacional do que para EBTs domésticas ou para EBTs que se internacionalizam de forma não acelerada. Muitas vezes, uma EBT atua no mercado internacional, mas não possui investimento direto estrangeiro (Oviatt \& McDougall, 1994) e não consegue desfrutar plenamente, ou desfruta de maneira diferente, dos recursos do país hospedeiro. Dessa forma, o país de origem pode ser uma importante fonte de recursos.

Fernhaber et al. (2003) e Fernhaber et al. (2008) apontam a necessidade de entender o papel da localização no processo de internacionalização dessas empresas. A localização geográfica da empresa, principalmente em termos de pertencer a um habitat de inovação no país de origem, isto é, pertencer a 
um parque tecnológico, uma incubadora de empresa, etc., aparece associado ao fenômeno born global (Crone, 2008; Ribeiro \& Pimentel, 2009). Em outras palavras, empresas born globals estão concentradas em habitat de inovação (Dib et al., 2010; Zucchella, 2002), pois a concentração geográfica, muitas vezes, pode favorecer a formação de redes de empresas similares e permite enfrentar o aumento da complexidade tecnológica e dos custos das atividades de pesquisa.

O Brasil possui 31 grandes parques tecnológicos em diferentes setores da economia. Outros 17 estão em fase de implantação, e 32 estão sendo projetados. A maior parte dos parques brasileiros foram iniciados a partir de 2005, e observa-se a aglomeração desses parques nas regiões Sudeste e Sul, devido à concentração da produção técnico científica dessas regiões (Associação Nacional de Entidades Promotoras de Empreendimentos Inovadores [ANPROTEC], 2011).

H1a: A entrada acelerada de EBTs born globals no exterior está associada positivamente à sua localização em habitats de inovação.

Há estudos que mostram EBTs born globals que nascem como fornecedoras de uma grande multinacional ou que nascem em setores altamente globalizados, ou seja, setores em que cadeias globais de fornecimento estão configuradas (Fernhaber, McDougall, \& Oviatt, 2007). Empresas que nascem nessas indústrias, num dado momento, por força das demandas de seus clientes, necessitam pensar uma estratégia de internacionalização rapidamente. Fernandes e Seifert (2007) argumentam que, nesses casos, as empresas são puxadas para o mercado internacional. Assim, a EBT deve se internacionalizar rápido em virtude das condições e das necessidades de fornecimento a seus clientes.

Estudos brasileiros, como o de Rodrigues e Almeida (2008), mostram a integração de EBTs de determinados setores a cadeias produtivas globais, como as atividades verificadas na indústria de software. Outro exemplo é o setor de produção de aviões. Devido à crescente complexidade tecnológica, que se reflete nos elevados custos de desenvolvimento de novos produtos, as fabricantes de aeronaves têm se concentrado nas atividades de projeto e montagem, demandando um amplo conjunto de componentes e serviços de uma cadeia de fornecedores globais (Fernhaber et al., 2007).

Por exemplo, a Embraer é responsável por $90 \%$ das receitas dos seus fornecedores brasileiros (Rodrigues \& Almeida, 2008). Isso caracteriza uma relação de alta dependência. Além disso, as empresas subcontratadas pela Embraer são, em geral, de pequeno porte, com menos de 50 funcionários. No entanto, esses fornecedores são altamente especializados e com elevada capacidade tecnológica em serviços de engenharia, usinagem e tratamento de superfícies (Reddy, 2011). Esse cenário impulsionou um processo de consolidação do setor, com destaque para a formação de um consórcio de pequenas e médias empresas voltado para a exportação, denominado High Technology Aeronautics (HTA). Esse movimento evidencia que tais empresas estão buscando caminhos internacionais, ligando-se à cadeia produtiva global de produção aeronaves.

H1b: A entrada acelerada de EBTs born globals no exterior está associada positivamente à integração em cadeias produtivas globais.

Outro fator apontado pela literatura como essencial para as empresas de internacionalização acelerada são as parcerias e alianças estratégicas com outras empresas, universidades ou institutos de pesquisa (Autio, Sapienza, \& Arenius, 2005; Coviello \& Munro, 1995; Dib et al., 2010; Oviatt \& McDougall, 1994). Os objetivos dessas parcerias vão desde a diminuição de riscos até a combinação de recursos essenciais, por exemplo, para o desenvolvimento conjunto de programas de P\&D, entre outros (Fernhaber et al., 2008; Fernhaber, Gilbert, \& McDougall, 2003). Nas empresas de pequeno porte, dada a limitada força organizacional e a limitação de recursos de várias naturezas, as ligações locais no país de origem são extremamente importantes para a competitividade e a inovação (Fernhaber et al., 2003).

Além disso, percebe-se o crescente número de multinacionais de grande porte que, em busca de recursos para facilitar a inovação e captar ideias geradas externamente, complementam suas áreas de P\&D formando redes de alianças estratégicas com EBTs born globals em diferentes países do mundo (Vapola, Tossavainen, \& Gabrielsson, 2008). 
H1c: A entrada acelerada de EBTs born globals no exterior está associada positivamente ao estabelecimento de parcerias com empresas multinacionais, universidades e institutos de pesquisa para inovação em seu país de origem.

A compreensão do impacto das políticas governamentais nos processos de internacionalização das born globals ainda é limitado (Bell, 1995; Loane \& Bell, 2006). As constatações muitas vezes não são baseadas em evidências empíricas, uma vez que poucos pesquisadores conseguiram investigar a relação positiva de políticas e dispêndios públicos para a internacionalização em termos de benefícios competitivos para as firmas ou benefícios de desenvolvimento para o país (McDougall \& Oviatt, 1996; Oviatt \& McDougall, 1999).

Assim, os esparsos resultados mostram que as políticas de incentivo nacionais à internacionalização das born globals acontecem de diversas maneiras, mas em geral, se traduzem em políticas de incentivos à exportação (Bell \& Mcnaughton, 2000). Todavia, na literatura internacional, alguns países são tidos como referência na formulação de políticas específicas para o desenvolvimento de vantagens competitivas de empresas que já nascem voltadas para o mercado internacional, como é o caso de Irlanda, Austrália, Coréia (Bell \& Mcnaughton, 2000; Loane \& Bell, 2006).

No Brasil, políticas recentes têm incentivado a internacionalização das empresas nacionais. A Agência Brasileira de Promoção de Exportação e Investimentos (APEX) e o BNDES têm concedido incentivos significativos nesse sentido. Em termos das born globals, o estudo de Ribeiro e Pimentel (2009) apresenta o caso da CI\&T, que se internacionalizou de maneira acelerada, com ajuda estatal via financiamento do Banco Nacional de Desenvolvimento Econômico e Social (BNDES) para o estabelecimento do primeiro contrato de grande porte nos EUA, em 2001. E, em 2005, foi aberta uma subsidiária na Filadélfia, numa operação de venture com o BNDES, que passou a deter $30 \%$ da empresa. Dessa forma, dar apoio à internacionalização de EBTs que possuem produção baseadas em conhecimento e produtos de alto valor agregado parece estar na agenda das políticas públicas em economias avançadas e emergentes e também ser alvo de preocupação por parte de universidades e empresas. Com o surgimento de empresas nascidas globais, o foco de investigação passa a ser a compreensão e o suporte dos processos de internacionalização de tais empresas (Bell, 1995; Loane \& Bell, 2006).

H1d: A entrada acelerada de EBTs born globals no exterior está associada positivamente à utilização de políticas governamentais e apoios do governo.

\section{Fatores internos}

As born globals, em geral, dispõem de muito menos recursos tangíveis, tais como instalações, recursos financeiros e humanos e, muitas vezes, elas têm pouca ou nenhuma experiência em seus mercados. Mesmo assim, essas empresas entram no mercado internacional e, em muitos casos, sobrevivem e conseguem obter retornos positivos em seus negócios. Tal fato é atribuído à posse de produtos de alto grau de conhecimento e especialização, que exigem inovação constante (Knight \& Cavusgil, 2004). A articulação de produtos únicos e da capacidade de constante inovação permite as born globals superar os seus concorrentes e internacionalizar-se mais rapidamente (Dib et al., 2010; Simões \& Dominguinhos, 2001).

Outros estudos também discutem a questão da capacidade de inovação da empresa (Knight \& Cavusgil, 2004) e a constante busca por diferenciação de produto que exigem constantes inovações como uma fonte de vantagem competitiva (Bloodgood, Sapienza, \& Almeida, 1996) ou vantagem tecnológica (Moen, 2002). Normalmente, essas empresas pertencem a indústrias nas quais os ciclos de vida dos produtos são curtos e requerem constante inovação e recursos especializados, difíceis de imitar. Na verdade, essas são as empresas que vendem produtos exclusivos ou serviços especializados como única forma de sobreviver no mercado internacional (Dominguinhos \& Simões, 2001; Oviatt \& McDougall, 1995). 
H2a: A entrada acelerada de EBTs born globals no exterior está associada positivamente à capacidade de inovação da empresa.

Segundo o estudo de Knight e Kim (2009) com 354 pequenas novas empresas norte-americanas, a orientação para o mercado internacional aparece como um dos construtos mais importantes na rápida entrada no exterior. Além da capacidade de inovação, as born globals se destacam por sua orientação para o mercado internacional, ou seja, por suas atividades internacionais orientadas para atender especificamente às demandas dos clientes internacionais, entender a ação dos concorrentes no mercado externo e conseguir coordenar as ações internacionais entre as áreas funcionais da empresa (Knight \& Kim, 2009).

O efeito positivo da orientação para o mercado sobre o desempenho da empresa está bem documentado em ambientes de negócios domésticos (Calantone, Kim, Schmidt, \& Cavusgil, 2006). No entanto, a natureza dos clientes e concorrentes no exterior difere substancialmente do mercado doméstico, e as born globals que têm a capacidade de utilizar adequadamente a inteligência de mercado para compreender e atender clientes no estrangeiro em geral atingem desempenho superior. Em geral, as empresas born globals, para atender a um determinado nicho, possuem estratégias de customização de produto e orientação para a necessidade dos clientes (Knight \& Cavusgil, 2004), e isso advém da sua orientação para o mercado internacional.

H2b: A entrada acelerada de EBTs born globals no exterior está associada positivamente à orientação para o mercado internacional.

O estudo de Knight e Cavusgil (2004) revelou que born globals, quando entram no exterior, precisam desenvolver e aplicar as habilidades de marketing. Atividades como publicidade, vendas diretas e técnicas promocionais são cruciais para a empresa conseguir entrar de forma rápida em um mercado internacional. Luostarinen e Gabrielsson (2006) estudaram as estratégias de preços, distribuição e propaganda de produtos.

Knight e Kim (2009) reforçam que as habilidades em marketing internacional referem-se à competência da empresa para criar valor para clientes estrangeiros por meio de segmentação e orientação de mercado. Cria-se valor também com a integração de atividades de marketing internacional, de planejamento, controle e avaliação para atender à preferência dos clientes internacionais e diferenciar as ofertas dos concorrentes. Questões como formas de distribuição e venda, preço do produto, adaptação ao consumidor local, imagem da empresa etc., podem apresentar significativa diferença em relação ao mercado doméstico (Calantone et al., 2006).

H2c: A entrada acelerada de EBTs born globals no exterior está associada positivamente à habilidade em marketing internacional.

\section{Fatores do empreendedor}

$\mathrm{Na}$ literatura internacional, prevalece a evidência de que o perfil do empreendedor e suas ações constituem elementos recorrentes e fundamentais na caracterização do fenômeno de internacionalização acelerada (Dominguinhos \& Simões, 2001).

Holtbrugge e Wessely (2009) argumentam sobre o conceito de habilidades gerenciais internacionais do empreendedor em estudos de born globals. São destacadas pelos autores as dimensões ligadas diretamente ao perfil do empreendedor, tais como sua formação técnica e gerencial, suas experiências acumuladas ao longo de sua carreira profissional empresarial e acadêmica, conhecimento de idiomas etc. (Dominguinhos \& Simões, 2001). Dentre as dimensões vinculadas às ações do empreendedor estão: sua capacidade de identificação de oportunidades no exterior (Andersson, 2000; Mathews \& Zander, 2007); a mobilização e o gerenciamento de recursos para a exploração dessas oportunidades (Mathews \& Zander, 2007); e a propensão a assumir riscos financeiros e de mercado, internacionalmente (Andersson, 2000). 
Dominguinhos e Simões (2001) argumentam que um dos principais entraves para a internacionalização de uma EBTs é o fato de muitas delas serem gerenciadas pelos próprios fundadores que, em geral, são pesquisadores ou inventores, e que, na maioria dos casos, não possuem perfil empreendedor e têm pouca ou nenhuma formação gerencial.

H3a: A entrada acelerada de EBTs born globals no exterior está associada positivamente à habilidade gerencial internacional do empreendedor.

Simões e Dominguinhos (2001) e Oviatt e McDougall (1994) apontam que, em empresas de internacionalização acelerada, os empreendedores têm, em geral, experiência profissional internacional, seja de trabalho anterior em multinacionais (em departamentos internacionais ou de exportação) seja via experiência no exterior como funcionários expatriados. Ou, ainda, em algum outro tipo de experiência profissional no mercado externo. Os autores mencionam, inclusive, experiências durante a formação desses profissionais, como cursos de MBAs no exterior.

Os empreendedores das EBTs são, em geral, pesquisadores de universidades que começam as suas próprias empresas ou são pessoas que possuem laços muito estreitos com o mundo acadêmico. É muito comum pesquisadores em busca dos conhecimentos científicos de suas áreas tratarem de obter esse conhecimento no exterior, realizando parte de suas pesquisas em um país estrangeiro ou até mesmo participando de congressos no exterior (Fernandes \& Seifert, 2007).

H3b: A entrada acelerada de EBTs born globals no exterior está associada positivamente à experiência internacional do empreendedor.

\section{Metodologia}

\section{População e amostra}

A população deste estudo é constituída por empresas de base tecnológica (pequeno e médio porte) que possuem atividade econômica de alta intensidade tecnológica. De acordo com a classificação da Organização para a Cooperação e o Desenvolvimento Econômico (OCDE, 2003), setores de alta tecnologia são: aeronáutica e aeroespacial, farmacêutica, informática, eletrônica, telecomunicações, instrumentos médicos de ótica e precisão. Escolheu-se alta tecnologia porque o fenômeno born global é mais recorrente em setores de maior densidade tecnológica, apesar de não ser excludente.

Há dificuldade de consolidar uma amostragem estatisticamente representativa de EBTs devido à inexistência de censos ou listagens completas desse tipo de empresa, e de poucos estudos com alcance nacional que caracterizem essa população no Brasil. No Brasil, os estudos de Pinho (2005); Côrtes, Pinho, Fernandes, Smolka e Barreto (2005); Toledo, Silva, Mendes e Jugend (2008) e Santos e Pinho (2010) estão baseados nos resultados de ampla pesquisa sobre as atividades, arranjos de cooperação, capacitação tecnológica, entre outros aspectos, das EBTs no Brasil. Esses estudos sobre EBTs relatam algumas barreiras estruturais do ambiente empresarial brasileiro que podem significar um entrave à atuação internacional dessas empresas, como deficiência das estruturas empresariais de funções administrativas e comerciais, fraqueza das redes de cooperação, dificuldades em relação à adequação e certificação do produto às normas internacionais, entre outros.

No entanto, o número de EBTs no Brasil ampliou-se nos últimos anos devido aos esforços governamentais e de entidades promotoras de empreendedorismo. Apesar de não existir um censo oficial sobre o número de EBTs brasileiras, dados da ANPROTEC (2011) apontam que existem hoje, no País, aproximadamente 6,3 mil empresas vinculadas a incubadoras e parques tecnológicos, e pouco mais de 1,5 mil empresas graduadas (que já passaram pela fase de incubação). Pinho (2005); Côrtes et al. (2005); Toledo et al. (2008) e Santos e Pinho (2010) retratam uma realidade das EBTs anterior a programas governamentais, como o Programa de Subvenção Econômica, e a projetos como o PRIME 
(Primeira Empresa Inovadora), que estão incentivando a criação de EBTs. E anterior também a uma nova tendência do governo favorável à inserção de empresas brasileiras no exterior como uma maneira de dinamizar a própria economia do País, como explica Coutinho, Hiratuka e Sabatini (2008).

Assim, para a construção da amostra, foram consultados vários tipos de fontes:

1. Listagens de parques tecnológicos e incubadoras associados da Associação Nacional de Entidades Promotoras de Empreendimentos Inovadores (ANPROTEC) que reconhecidamente possuem empresas de setores de alta tecnologia, como os de material aeronáutico (São José dos Campos SP), eletrônico (Santa Rita de Sapucaí - MG) e biotecnologia (Belo Horizonte - MG); Porto Digital (Recife - PE); Parque da Unicamp (Campinas - SP), Parques de São Carlos (São Carlos - SP), entre outros.

2. Listagens de programas governamentais da Agência Brasileira de Promoção a Exportação e Investimentos (APEX), de incentivo à internacionalização de setores de alta tecnologia.

3. O estudo de Pinho (2005) sobre resultados de ampla pesquisa sobre as atividades, arranjos de cooperação, capacitação tecnológica, entre outros aspectos, das EBTs no Brasil. E a também o estudo de Dib et al. (2010) único estudo quantitativo sobre born globals no Brasil. Dib et al. (2010) se preocupou com o setor de software brasileiro e identificou 35 empresas de internacionalização acelerada desse setor.

Assim, devido à incerteza do número da população, a natureza da amostra, neste estudo, não teve a pretensão de atender critérios de representatividade estatística da população e se constitui numa amostra não probabilística e intencional (Hair, Black, Andersson, \& Tatham, 2005). Embora, em princípio, fosse desejável uma amostra probabilística, a inexistência de listagens e censos completos de EBTs de setores de alta tecnologia e de estudos prévios com alcance nacional que caracterizem essa população torna impraticável a montagem de amostras com esse grau de rigor. Nesse contexto, o objetivo foi compor uma amostra abrangente, sendo essa abrangência definida particularmente com referência à cobertura: (a) de setores em que tipicamente se desenvolvem atividades de EBTs de alta tecnologia; e (b) das principais regiões do Brasil em que há indicações prévias da existência desse tipo de empresa.

Ao final do período de coleta de dados, foram excluídas as empresas de capital societário majoritariamente estrangeiro e, como o foco do estudo eram pequenas e médias empresas, segundo critério do IBGE, também foram excluídas empresas com mais de 249 funcionários.

A primeira base de dados gerada continha 214 respostas. Dessas 214, foram obtidas 114 respostas que eram de empresas com operação somente no Brasil, e 85 respostas de empresas que possuem algum tipo de negócios no exterior, 39,7\%.

Neste trabalho, o objetivo é avaliar os fatores relevantes na rápida internacionalização das EBTs. Assim as EBTs que atuam essencialmente no mercado brasileiro não foram analisadas. Das 85 EBTs com algum tipo de negócio no exterior, 31 respostas, havia um grande número de dados faltantes (missing values) em relação às respostas referentes às variáveis independentes e principalmente pelo fato de elas não indicarem o ano da primeira atividade internacional, logo não possibilitando a classificação de Born Global. Hair, Black, Andersson e Tatham (2005) apresentam duas formas de lidar com esse tipo de problema. A primeira delas é a identificação de respondentes que demonstram um grande número de informações faltantes, sendo estes eliminados da análise. A segunda maneira é a da estimativa dos valores faltantes, substituindo-os pela média. Neste estudo, optou-se por eliminar da análise os respondentes que apresentavam omissão de respostas. Assim, foram considerados 54 questionários válidos na análise do modelo.

Logo, optou-se por eliminar da análise os respondentes que apresentavam dados faltantes (Hair et al., 2005). Assim, foram considerados 54 questionários válidos. 
Segundo a classificação da OCDE (2003), as empresas da amostra compreendem oito setores, a saber: $24 \%$ (13) das empresas são do setor de tecnologia da informação; $20 \%$ (11) dos setores eletrônico e de telecomunicações; $17 \%$ (9) são de serviços especializados; $15 \%$ (8) do setor de biotecnologia; $11 \%$ (6) são empresas midium-high tech; $9 \%$ (5) do setor aeronáutico e aeroespacial; e $4 \%$ (2) do setor de instrumentos óticos e de precisão. Segundo classificação de tamanho de empresas por número de funcionários, $43 \%$ (23) são microempresas (menos de dez empregados), outros $43 \%$ pequenas empresas (entre dez e 49 empregados) e 15\% (8) são médias empresas (entre cinquenta e duzentos e quarenta e nove empregados). Não existem grandes empresas na amostra.

Numa análise comparada entre as 54 empresas usadas e as 31 não usadas, percebe-se que, em termos de tamanho, enquanto a primeira amostra tinha $43 \%$ de micro empresas, na amostra das não respondentes o percentual é de $49 \%$ de micro e pequenas empresas. O que caracteriza a pequena variação entre os respondentes e os não respondentes. Ademais, em relação aos setores da amostra das empresas usadas e das empresas descartadas, segue o mesmo padrão. A maioria das empresas é do setor de TI ( $24 \%$ das respondentes e $29 \%$ das empresas descartadas), seguido pelo setor de telecomunicações e eletrônica ( $20 \%$ das respondentes e $14 \%$ das descartadas) e pelo setor de serviços especializados ( $17 \%$ das respondentes e $20 \%$ das descartadas).

\section{Construção do questionário e coleta de dados}

O questionário foi desenvolvido com escalas Likert de cinco pontos. Cada uma das variáveis operacionais propostas está relacionada a pelo menos três questões de escala intervalar. Na redação das perguntas aqui aplicadas, além da revisão da literatura sobre internacionalização acelerada, quando possível, foram comparados questionários aplicados em outros contextos e adaptações foram feitas às escalas e às perguntas para sua adequação aos respondentes brasileiros.

O questionário foi analisado para validação por um grupo de estudiosos dos negócios internacionais. Logo após a validação dos estudiosos, pré-testes foram realizados. Em seguida, feitos os ajustes, o questionário foi enviado para que o fundador (empreendedor) ou um executivo que trabalha diretamente com as operações internacionais de cada EBT o respondesse. A coleta de dados se deu por meio de questionário eletrônico autoadministrado (Hair et al., 2005). O questionário foi disponibilizado em website, com ajuda de um software especializado, ficando à disposição dos respondentes no período de 10/05/2011 a 15/07/2011.

Para realizar a pesquisa, foi preciso obter e consolidar uma lista de endereços eletrônicos dos potenciais respondentes. Nesse sentido, primeiramente foram contatados os coordenadores dos parques tecnológicos, via e-mail e telefone, contato este destinado a explicar os objetivos da pesquisa e solicitar uma listagem dos empreendedores das EBTs. Quando não foi possível contatar nenhum responsável pelo parque tecnológico, utilizou-se a internet (web-site oficial do parque ou da incubadora, e até mesmo web-site da empresa, quando havia) para obter a lista de contato dos empreendedores. Preliminarmente, contatou-se a empresa, via e-mail, com a intenção de convidá-la a participar da pesquisa. Quando esta não respondia, era feito o contato telefônico para o convencimento dos respondentes, seguido de um e-mail com o link do questionário para ser respondido. Contatou-se também a direção da ANPROTEC, para a divulgação da pesquisa no web site da instituição com um link direto para o questionário.

Grande parte das pesquisas recentes sobre born globals que se propõem a coletar dados primários são feitas via questionário eletrônico, como os estudos de Knight e Kim (2009), Knight e Cavusgil (2004) e Dib et al. (2010). Tal como todas as ferramentas de coleta de dados, o uso do questionário eletrônico possui vantagens e limitações. Entre as vantagens dessa ferramenta estão a rapidez das respostas, os custos mais baixos e a maior facilidade de disseminação entre as empresas pesquisadas. Suas principais limitações dizem respeito às baixas taxas de respostas e ao uso de amostras que podem não ser representativas da população pesquisada (Hair et al., 2005). 


\section{Construção das variáveis}

A variável dependente do modelo de análise entrada acelerada no exterior será considerada em termos do Tempo entre a fundação e a primeira operação no exterior. Neste trabalho é adotado o conceito operacional de born global estabelecido por Dib et al. (2010) por ser o único trabalho quantitativo sobre esse tipo de empresa no Brasil. A definição está alinhada com os principais trabalhos internacionais sobre esse conceito (Knight \& Cavusgil, 2004; Knight \& Kim, 2009; Madsen \& Servais, 1997; Oviatt \& McDougall, 1994, 1995; Rialp et al., 2005). Assim, é considerada born global a empresa que, num horizonte de tempo de até cinco anos desde sua fundação, já realizou negócios em pelo menos um mercado internacional (Dib et al., 2010). Restrições não foram feitas sobre a percentagem de receitas provenientes de operação no exterior, nem sobre a cobertura de mercado ou países atendidos, que poderá(ão) ser um ou vários (Dib et al., 2010).

A variável independente fatores externos à empresa foi construída de acordo com os modelos de Madsen e Servais (1997); Zahra e George (2002) Fernhaber et al. (2008). As questões checam o impacto dos seguintes fatores, no processo de internacionalização da EBT.

Localização em um habitat de inovação (Alpha de Cronbach 0,780). Essa variável é adaptada do estudo de Fernhaber et al. (2008), que considera localização em um habitat de inovação, a localização em um parque tecnológico, incubadora, Aceleradora, APL. Assim o constructo foi formado por quatro variáveis: pertencer a um habitat de inovação facilitou a entrada de sua empresa no exterior; para ser reconhecida no mercado internacional, sua empresa utiliza o nome do seu habitat de inovação; o seu habitat de inovação the deu assessoria de planejamento estratégico para sua empresa atuar no exterior; o apoio de recursos (equipamentos, laboratórios, serviços especializados, estruturas comerciais de compra de insumos e venda de produtos) do habitat de inovação acelerou a internacionalização de sua empresa. Integração a cadeias produtivas globais (Alpha de Cronbach $0,814)$. Essa variável está relacionada ao fato da articulação da empresa como fornecedora em cadeias produtivas globais ou competição em um setor altamente internacionalizado (Fernhaber et al., 2007). Assim, o constructo é formado por cinco variáveis: atuar em um setor integrado internacionalmente acelera a necessidade de internacionalização de sua empresa; ser fornecedor de produto ou serviço de uma grande multinacional acelera a internacionalização de sua empresa; para competir em seu setor, internacionalizar atividades é uma questão de sobrevivência; a internacionalização de seu principal cliente gera a necessidade de rápida internacionalização de sua empresa para continuar o fornecimento; competir em um setor em que seus concorrentes diretos atuam no exterior acelera a internacionalização de sua empresa. Parcerias e alianças estratégicas para inovação (Alpha de Cronbach 0,715). Essa variável é adequada do estudo Gabrielsson e Kirpalani (2004), que mostra diferentes formas de utilização de parcerias das born globals para conseguir entrar em mercados internacionais. No caso dessa variável, foram examinadas as parcerias da empresa no país de origem. Assim, as questões checam o auxílio na internacionalização de: parcerias com universidades brasileiras; projeto de P\&D conjunto com multinacionais situadas no Brasil; parcerias com centros ou institutos de pesquisa brasileiros. Políticas governamentais (Alpha de Cronbach 0,613). Essa variável está baseada em Bell e Mcnaughton (2000), que mostram a utilização de políticas (projetos, financiamentos) governamentais de apoio à internacionalização das born globals. As questões conferem o auxílio na internacionalização de: utilização de financiamento público para atuação no exterior; participação em projetos de entidades governamentais de apoio à exportação; acordos internacionais feitos pelo governo brasileiro; políticas tarifárias do governo brasileiro.

A variável independente fatores internos da empresa foi construída de acordo com os modelos de Knight e Kim (2009); Gabrielsson e Kirpalani (2004); Knight e Cavusgil (2004) e foi composta pelos fatores a seguir.

Capacidade de inovação (Alpha de Cronbach 0.856). Variável baseada nos estudos de Knight e Cavusgil (2004) e Knight e Kim (2009), que definem inovação como a capacidade da empresa para desenvolver e introduzir novos produtos, serviços, processos gerenciais ou ideias para o mercado internacional. As questões verificam essas diversas faces da inovação e seu papel na internacionalização acelerada: nossa empresa está na vanguarda tecnológica da nossa indústria nos 
mercados internacionais; nós desenvolvemos grande parte da tecnologia contida em nosso produto; na concepção e na fabricação de nosso produto, empregamos alguns dos especialistas mais qualificados da indústria; somos reconhecidos no mercado internacional por produtos que são tecnologicamente superiores; comparados com os concorrentes locais, somos muitas vezes os primeiros a introduzir inovações de produto ou de novas abordagens de operação nos mercados internacionais; possuímos gastos formais com P\&D de novos produtos.

Orientação para o mercado internacional (Alpha de Cronbach 0.803). Variável fundamentada no estudo de Knight e Kim (2009). É a habilidade da empresa de entender a ação dos concorrentes, e conseguir coordenar as ações internacionais entre as áreas funcionais da empresa. É mediada pelas atividades internacionais orientadas para atender especificamente as demandas dos clientes internacionais. As perguntas verificam essa habilidade na internacionalização acelerada: os pontos fortes e fracos do nosso principal concorrente internacional; se um concorrente lançar uma campanha intensiva orientada para os nossos clientes internacionais, implementamos uma resposta imediatamente; funções do negócio (comercialização/vendas, finanças, produção etc.) integradas para atender às necessidades do mercado internacional; se a estratégia da empresa é baseada nas necessidades dos clientes internacionais; se a satisfação dos clientes internacionais com os produtos ou serviços é medida sistematicamente.

Habilidades de marketing internacional (Alpha de Cronbach 0.903). Também fundamentada no estudo de Knight e Kim (2009). É definida como a habilidade da empresa em criar valor para os clientes internacionais por meio de uma efetiva segmentação e avalia como as ferramentas de marketing estão organizadas para diferenciar as ofertas dos seus competidores. Assim, o constructo é formado por seis variáveis: processo de planejamento de marketing internacional; habilidade para segmentar e identificar nichos de mercado no exterior; habilidade para usar ferramentas de marketing para diferenciar o produto (design, formar preço, fazer publicidade); desenvolvimento e adaptação do produto no mercado internacional; imagem da empresa; reconhecimento mundial do produto/serviço.

A variável independente fatores do empreendedor baseia-se nos modelos de Simões e Dominguinhos (2001) e Oviatt e McDougall (1994), e foi construída pelos fatores a seguir.

Habilidade gerencial internacional do empreendedor (Alpha de Cronbach 0.813). Essa variável é adaptada de Holtbrugge e Wessely (2009), que considera que as habilidades gerenciais internacionais derivam do perfil (formação técnica e gerencial, experiências acumuladas ao longo da carreira, conhecimento de idiomas) e das ações dos empreendedores: capacidade de identificação de oportunidades no exterior, mobilização e gerenciamento de recursos para a exploração dessas oportunidades, e propensão a assumir riscos financeiros e de mercado, internacionalmente; visão dos gerentes em relação ao mercado internacional; direcionamento dos empreendedores na decisão de entrar em mercados estrangeiros; formação gerencial do empreendedor na entrada da empresa no exterior; habilidade dos gerentes com o idioma; processo de seleção de pessoas com competências para atuação em mercados internacionais; habilidade dos profissionais da empresa em trabalhar com pessoas de outros países, com culturas diferentes; adaptação dos profissionais a outros países e culturas; habilidade dos gerentes em identificar oportunidades de negócio no exterior.

Experiência profissional internacional (Alpha de Cronbach 0.625). Variável baseada em Dominguinhos e Simões (2001). A experiência profissional internacional é definida como trabalho anterior em multinacionais (em departamentos internacionais ou de exportação) ou através da experiência no exterior como funcionários expatriados. Ou, ainda, algum outro tipo de experiência profissional no exterior, como experiências durante a formação desses profissionais, como cursos de MBAs no exterior etc. As questões checam: a experiência anterior de trabalho do empreendedor em empresas multinacionais no Brasil (em departamentos internacionais ou de exportação); a experiência anterior de trabalho do empreendedor, no exterior, como funcionário expatriado de empresa sediada no Brasil; a experiência educacional no exterior (MBA, doutorado, cursos); os relacionamentos pessoais do empreendedor no exterior; a origem familiar do empreendedor. 


\section{Técnicas estatísticas}

Neste estudo, o modelo da regressão logística foi estimado para avaliar se e em que medida cada uma das variáveis independentes contribui para a rápida entrada da EBT no exterior. Testou-se a significância dos coeficientes das variáveis independentes dos fatores externos, utilizando-se para tal a estatística Wald, e considerou-se que, quando o nível de significância estatística $p<0,05$, o coeficiente é útil para o modelo (Hair, Black, Babin, Anderson, \& Tatham, 2006). A significância do modelo final pode ser observada na medida Hosmer e Lemeshow de ajuste geral, cujo foco não é rejeitar Ho: não existe diferença significante entre as classificações observadas e previstas.

Ademais, foram usados como variáveis de controle os setores de atividades das empresas e o tamanho delas. Tratam de variáveis dummies que representam sete setores e três categorias de tamanhos descritos no perfil da amostra.

A regressão logística é uma técnica mais robusta a ser aplicada quando as condições satisfatórias para a análise discriminante não são atendidas, em especial, para casos em que a amostra é pequena e a normalidade das variáveis independentes não é obtida (Hair et al., 2006). Em relação à normalidade, Maroco (2010) salienta que, quando não for satisfeito, esse aspecto causa um impacto não significativo no resultado, podendo, portanto, ser aplicada a regressão logística nos casos de ausência de normalidade.

Em relação ainda ao tamanho reduzido da amostra, é importante destacar que esse artigo segue as recomendações de Vittinghoff, Sen e McCulloch (2009), em que o objetivo da pesquisa não é fazer predições, mas apenas testar a influência das variáveis em relação à variável dependente. Isso porque, na regressão logística, o método tradicional de estimativa de razões de chance é o da máxima verossimillhança que, em relação às amostras pequenas, pode acarretar resultados não adequados (Nemes, Jonasson, Genell, \& Steineck, 2009).

Dessa forma, como na presente pesquisa foi obtido um número reduzido de respostas, ou seja, de cinquenta e quatro empresas, e constatada a ausência de normalidade nas variáveis independentes, optou-se pela técnica estatística da regressão logística para estimar a associação das variáveis independentes em relação ao fenômeno dependente estudado.

\section{Apresentação e Discussão dos Resultados}

Inicialmente procedeu-se à identificação e à separação das EBTs em termos de seus processos de internacionalização, tendo sido identificadas 33 (62\%) empresas born globals - empresas internacionalizadas que atendiam aos critérios da pesquisa para serem consideradas born globals, ou seja, que levaram menos de cinco anos para obter seu primeiro faturamento proveniente de ações no exterior. Enquanto foram 21 (38\%) empresas classificadas como Internacionais Tradicionais ou EBTs não born globals - EBTs internacionalizadas que entraram no mercado internacional com mais de 5 anos de atuação no mercado doméstico

Na Tabela 1, todas as correlações entre os pares de variáveis independentes podem ser consideradas baixas, sendo que 6 , dentre as 36 possíveis, podem ser consideradas significativas ao nível de $1 \%(p<0,01)$ e 7 pares de variáveis apresentam correlações ao nível de $5 \%(p<0,05)$. Isso denota a pouca possibilidade de multicolinearidade entre os constructos apresentados. Além disso, a realização do teste VIF (Tabela 2, última coluna) mostra a ausência de multicolinearidade, ou seja, VIF menor que 5 (Hair et al., 2006). 
Tabela 1

Correlação entre as Variáveis Independentes do Modelo

\begin{tabular}{lccccccccccc}
\hline \multicolumn{10}{c}{ Correlações } \\
\hline & Média & Desvio & LOC & INT & PAR & POL & INOV & MINT & MKT & GER & EXP \\
LOC & 3,02 & 0,98 & 1 & & & & & & & & \\
INT & 3,11 & 0,88 &, 189 & 1 & & & & & & & \\
PAR & 2,46 & 0,96 &, 050 &, 120 & 1 & & & & & & \\
POL & 1,83 & 0,75 &, $405^{* *}$ &, 236 &, $292^{*}$ & 1 & & & & & \\
INOV & 3,82 & 0,75 &, 161 &, 021 &, 106 &, 199 & 1 & & & & \\
MINT & 3,13 & 0,80 &, 100 &, $285^{*}$ &, 121 &, 252 &, $298^{*}$ & 1 & & & \\
MKT & 2,95 & 0,75 &, 081 &, $371^{* *}$ &, 054 &, 092 &, 157 &, $275^{*}$ & 1 & & \\
GER & 4,05 & 0,66 &,- 067 &, $302^{*}$ &,- 089 &, 121 &, $269^{*}$ &, $390^{* *}$ &, $349^{* *}$ & 1 & \\
EXP & 2,52 & 0,73 &, 169 &, 197 &, 259 &,- 106 &, $273^{*}$ &, $384^{* *}$ &, $368^{* *}$ &, 169 & 1 \\
\hline \multicolumn{1}{c}{ (1) } & & & & & & & \\
\hline
\end{tabular}

Nota. Fonte: elaborado pelos autores.

$\mathrm{Na}$ Tabela 2, é apresentado o modelo de regressão logística em que estão indicados os coeficientes da função logística para os fatores externos, internos e do empreendedor. O modelo 1 apresenta as variáveis de controle do perfil da amostra: setores de atividade e tamanho da empresa. Percebe-se a ausência de significância, já que nenhuma das duas categorias explica o fato da empresa ter uma internacionalização acelerada ou não.

Tabela 2

Regressão Logística para os Fatores Externos, Internos e do Empreendedor

\begin{tabular}{|c|c|c|c|c|c|c|}
\hline & Mod 1 & Mod 2 & Mod 3 & Mod 4 & Mod 5 & VIF \\
\hline Constante & 0,215 & 4,782 & 1.761 & -3.654 & $-1,029$ & \\
\hline LOC & - & $-2.095^{*}$ & - & - & $-2.038^{*}$ & 1.476 \\
\hline INT & - & $3.596^{*}$ & - & - & $3.313^{*}$ & 1.346 \\
\hline PAR & - & $-1.846^{*}$ & - & - & $-2.002 *$ & 1.299 \\
\hline POL & - & $-1.620^{*}$ & - & - & $-1.867^{*}$ & 1.753 \\
\hline INOV & - & - & -0.421 & - & $--\mathrm{X}--$ & 1.437 \\
\hline MINT & - & - & 0.191 & - & $--\mathrm{x}-$ & 1.612 \\
\hline MKT & - & - & -0.025 & - & $--\mathrm{X}--$ & 1.439 \\
\hline GER & - & - & - & $1.279^{*}$ & $1.818 !$ & 1.529 \\
\hline EXP & - & - & - & $-0,301$ & $--\mathrm{X}--$ & 1.764 \\
\hline microempresa & 1,154 & $--\mathrm{X}--$ & $--\mathrm{X}-$ & $--\mathrm{x}-$ & $--\mathrm{X}--$ & $--\mathrm{X}--$ \\
\hline pequena &, 227 & $--\mathrm{x}--$ & $--\mathrm{X}-$ & $--\mathrm{x}-$ & $--\mathrm{X}--$ & $--\mathrm{X}--$ \\
\hline aeroespacial &, 532 & $--\mathrm{X}--$ & $--\mathrm{X}-$ & $--\mathrm{X}--$ & $--\mathrm{X}--$ & $--\mathrm{X}--$ \\
\hline
\end{tabular}


Tabela 2 (continuação)

\begin{tabular}{|c|c|c|c|c|c|c|}
\hline & Mod 1 & Mod 2 & Mod 3 & Mod 4 & Mod 5 & VIF \\
\hline biotecnologia &,- 420 & $--\mathrm{X}--$ & $--\mathrm{X}--$ & $--\mathrm{X}--$ & $--X--$ & $--X--$ \\
\hline $\mathrm{TI}$ &, 346 & $--\mathrm{X}--$ & $--\mathrm{X}--$ & $--\mathrm{X}--$ & $--X--$ & $--X--$ \\
\hline eletro-telecom & $-1,063$ & $--\mathrm{X}--$ & $--\mathrm{X}--$ & $--\mathrm{X}--$ & $--\mathrm{X}--$ & $--X--$ \\
\hline otica e precisão & $-1,418$ & $--\mathrm{X}--$ & $--\mathrm{X}--$ & $--\mathrm{X}--$ & $--\mathrm{X}--$ & $--\mathrm{X}--$ \\
\hline midium-high &,- 383 & $--\mathrm{X}--$ & $--\mathrm{X}--$ & $--\mathrm{X}--$ & $--\mathrm{X}--$ & $--\mathrm{X}--$ \\
\hline Nagelkerke R Square & - & 0,697 & 0,025 & 0,183 & 0,747 & \\
\hline Cox \& Snell R Square & - & 0,504 & 0,018 & 0,132 & 0,540 & \\
\hline Hosmer e Lemeshow & - & $\begin{array}{c}5,024 \\
(p=0.755)\end{array}$ & $\begin{array}{c}11,006 \\
(p=0.198)\end{array}$ & $\begin{array}{c}12,591 \\
(p=0.127)\end{array}$ & $\begin{array}{c}12,227 \\
(\mathrm{p}=0.150)\end{array}$ & \\
\hline
\end{tabular}

$! \mathrm{p}<0,10 * \mathrm{p}<0,05 * * \mathrm{p}<0,01$

Nota. Fonte: elaborado pelos autores.

O modelo 2 apresenta apenas a relação dos fatores externos com a variável dependente. $\mathrm{O}$ resultado mostra que integração na cadeia de valor está associada com a internacionalização das EBT born globals, enquanto a localização em um habitat de inovação, a realização de parcerias e a utilização de políticas estão associadas à internacionalização das EBTs não born globals. O modelo 3 mostra que os fatores do ambiente interno não apresentam associação com a internacionalização das EBTs. Em relação aos fatores do empreendedor, o modelo 4 mostra que a habilidade gerencial do empreendedor tem associação com a internacionalização das EBTs born globals. Por fim, o modelo 5, que apresenta as variáveis significantes dos três níveis de análise, mostra que o ambiente externo tem uma associação significativa em relação à internacionalização das EBTs born globals e não born globals, e secundariamente, a habilidade do empreendedor está associada à internacionalização das EBTs born globals. A Tabela 3 sumariza as hipóteses em relação aos resultados encontrados.

Tabela 3

\section{Resumo do Teste das Hipóteses Ligadas aos Fatores Externos}

\section{Fatores externos}

H1a: A localização em habitats de inovação acelera a entrada de EBTs no exterior.

Invertida

H1b: A integração em cadeias produtivas globais acelera a entrada de EBTs no exterior.

Apoiada

H1c: A utilização de parcerias com empresas multinacionais, universidades e institutos de

Invertida pesquisa para inovação em seu país de origem acelera a entrada de EBTs no exterior.

H1d: A utilização de políticas governamentais e apoios do governo para internacionalização Invertida acelera a entrada de EBTs no exterior.

\section{Fatores Internos}

H2a: A capacidade de inovação acelera a entrada de EBTs no exterior.

Não apoiada

H2b: A orientação para o mercado internacional acelera a entrada de EBTs no exterior.

Não apoiada

H2c: A habilidade em marketing internacional acelera a entrada de EBTs no exterior.

Não apoiada

\section{Fatores do Empreendedor}

H3a: A habilidade gerencial internacional do empreendedor acelera a entrada de EBTs no exterior.

H3b: A experiência internacional do empreendedor acelera a entrada de EBTs no exterior.

Não apoiada

Nota. Fonte: elaborado pelos autores. 
Assim, em relação aos fatores externos, a hipótese confirmada é que a integração da empresa em cadeias produtivas globais está associada à internacionalização de EBTs born globals. Esse resultado apresenta conformidade com alguns estudos que mostram que inúmeras EBTs born globals nascem como fornecedoras de uma grande multinacional ou que nascem em setores altamente globalizados, ou seja, setores em que cadeias globais de fornecimento estão configuradas, como o setor aeronáutico, de software, entre outros (Fernhaber et al., 2007). Empresas que nascem nessas indústrias, num dado momento, por força das demandas de seus clientes globais, necessitam pensar, de forma bastante rápida, em uma estratégia de internacionalização. As EBTs born globals aqui estudadas parecem ser puxadas para o mercado internacional (Fernandes \& Seifert, 2007) em virtude das condições e das necessidades de fornecimento de seus clientes já instalados no mercado externo.

No entanto, um resultado interessante é que três, das quatro hipóteses testadas, para os fatores externos foram comprovadas de maneira invertida. Assim, a maioria dos fatores externos tem influência no processo de internacionalização das EBTs, mas não são fatores importantes para as EBTs se tornarem born globals. Isto significa dizer que, quanto mais a EBT possui experiência no mercado doméstico, mais ela consegue usufruir favoravelmente de seu processo de internacionalização de fatores, como: localização em um habitat de inovação; parcerias com universidades, institutos de pesquisa e empresas multinacionais; e também utilizar políticas governamentais de apoio à internacionalização.

A comprovação das hipóteses de maneira invertida, nesta pesquisa, parece indicar resultados distintos dos apresentados pelos principais estudos de fatores externos sobre born globals (Fernhaber et al., 2008; Zahra \& George, 2002). A literatura propunha que, para uma EBT born global (iniciante e pequena), o país de origem teria uma importância maior para sua atuação internacional do que para EBTs que se internacionalizam de forma não acelerada. Entretanto, o resultado da presente pesquisa, pautada em um país emergente, levanta suposições para o quanto as condições institucionais defasadas desses países podem se tornar uma condição para o atraso da internacionalização das empresas, em especifico as EBTs.

Ao contrário da maior parte das conclusões dos estudos sobre born globals, os fatores organizacionais ou fatores internos não apareceram como relevantes no processo de internacionalização das EBTs brasileiras. Isto significa dizer que capacidade de inovação, orientação para o mercado internacional e habilidades de marketing internacional não são fatores que diferenciam as EBTs born globals das EBTs de internacionalização com mais de cinco anos de atuação doméstica.

Não se está afirmando, contudo, que tais fatores não têm importância para as EBTs, porquanto na própria definição de empresa de base tecnológica a capacidade de inovação é, por exemplo, um elemento essencial. O que os resultados deste estudo atestam é que os fatores internos não são fatores diferenciadores. Fato que é admitido por certos estudos especializados na internacionalização de empresas de países emergentes, que apontam a carência de capacidades diferenciadores dessas empresas, exceto em processos de baixo custo, como fator impulsionador para uma internacionalização em busca de recursos no exterior (Bartlett \& Ghoshal, 2000; Guillén \& GarcíaCanal, 2009; Mathews, 2006).

Por fim, o resultado em relação à habilidade gerencial internacional do empreendedor suporta a literatura de born globals, no sentido de que é um fator que acelera a entrada da empresa no exterior (Andersson, 2000; Madsen \& Servais, 1997; Simões \& Dominguinhos, 2001). A habilidade gerencial internacional do empreendedor diz respeito às dimensões ligadas diretamente ao perfil do empreendedor (como sua formação técnica e gerencial, as experiências acumuladas ao longo de sua carreira profissional, empresarial e acadêmica), e às dimensões vinculadas às ações do empreendedor (sua capacidade de identificação de oportunidades no exterior, mobilização e gerenciamento de recursos para a exploração dessas oportunidades, propensão a assumir riscos financeiros e de mercado internacionalmente).

Ainda em relação aos fatores ligados ao empreendedor, a hipótese de experiência internacional não demonstrou ser comprovada empiricamente. A literatura born globals também é controversa em 
relação a esse fator. Para alguns estudos, a experiência internacional do empreendedor é uma condição necessária à expansão internacional de uma empresa, mas principalmente cria a motivação e a ambição para fazer a empresa se tornar uma born global, entre outros fatores, porque isso muda a percepção da distância de outros países (Andersson, 2000; Dominguinhos \& Simões, 2001; Madsen \& Servais, 1997; Oviatt \& McDougall, 1994). No estudo de Dib et al. (2010), acerca das born globals de software brasileiras, a questão da experiência internacional e a da educação no exterior dos empreendedores, unidas em uma mesma hipótese, também não obtiveram sustentação empírica.

\section{Conclusões}

A comprovação dos resultados permite afirmar que, considerando-se as empresas brasileiras de base tecnológica, é mais provável que sejam born globals aquelas que:

1. estão integradas a uma cadeia produtiva global;

2. possuem um empreendedor ou um grupo de principais executivos com habilidades gerenciais internacionais.

As conclusões acima estão em concordância com a literatura de born globals, que mostra que as empresas são puxadas rapidamente para o mercado internacional, em virtude das condições e necessidades de fornecimento de seus clientes já internacionais. As habilidades gerenciais internacionais do empreendedor também aparecem nos principais estudos sobre born globals como essenciais para uma rápida expansão internacional, particularmente na coordenação de recursos globalmente dispersos. Os executivos apresentam pró-atividade e uma mentalidade empreendedora para ações internacionais.

Entretanto, alguns resultados da presente pesquisa parecem divergir da tendência apresentada pelos principais estudos de born globals, mostrando que as empresas de países emergentes se comportam de maneira diferente das empresas de países desenvolvidos. Neste estudo, foi possível verificar a existência de diferentes comportamentos das EBTs em relação à internacionalização. Também se constatou que, diferentemente das EBTs born globals, as EBTs que demoram mais de cinco anos para entrar no mercado internacional usufruem mais, em seu processo de internacionalização, da localização em um habitat de inovação, das parcerias com universidades, institutos de pesquisa e empresas multinacionais, e das políticas governamentais de apoio à internacionalização.

Esses resultados mostram o papel essencial dos fatores externos para as EBTs com mais tempo de atuação no mercado doméstico, antes destas se deslocarem para o mercado externo.

Tal como os fatores externos, os fatores internos aqui testados parecem estar em desacordo com a tendência apontada pelos estudos sobre born globals. Bastante recorrentes na literatura internacional, os fatores internos ou organizacionais não apresentaram relevância no processo de internacionalização das EBTs brasileiras aqui estudadas.

Novamente, a comparação dos fatores que levariam empresas de um país emergente, como o Brasil, a entrar rapidamente no exterior parece apresentar diferenças dos fatores que impulsionariam a internacionalização acelerada de uma empresa nascente de alta tecnologia norte-americana, europeia ou japonesa.

As limitações do estudo devem ser reconhecidas. Primeiro, trabalhou-se com uma amostra não probabilística, que impede o pesquisador de calcular uma amostra estatisticamente confiável. O objetivo foi compor uma amostra abrangente, em termos de cobertura (a) de setores em que tipicamente se desenvolvem atividades de EBTs de alta tecnologia e (b) das principais regiões do Brasil em que há indicações prévias da existência desse tipo de empresa. 
A representatividade da amostra, no que se refere aos setores de base tecnológica no Brasil, foi prejudicada pela inexistência de censos ou listagens completas de dados oficiais abrangentes sobre esse tipo de empresa, forçando o uso de diversas listas para sua consolidação. O fato de a amostra de empresas internacionalizadas e, principalmente, das born globals, ser relativamente pequena, prejudica o teste da real capacidade discriminante dos modelos, por não permitir a divisão das amostras para análise.

No entanto, é preciso chamar a atenção para o número reduzido de EBTs brasileiras que possuem algum tipo de negócio no exterior. Não obstante isso, o número de EBTs no Brasil apresenta uma tendência de crescimento, e os estudos de internacionalização têm mostrado uma propensão a um maior envolvimento dessas empresas no exterior. Assim, estudos posteriores se propondo a investigar um número maior de EBTs internacionalizadas, que tendem a proliferar nos próximos anos, podem contribuir para elucidar melhor o tema em questão. Outra importante contribuição poderia ser comparar o comportamento born global com outras realidades de países emergentes.

No que tange à metodologia, estudos de caso, apesar de menos abrangentes que a survey, podem ser interessantes para aprofundar as discussões acerca da internacionalização acelerada no Brasil, principalmente estudos de casos longitudinais. Essa técnica também poderia ser interessante para averiguar as tendências contrárias apresentadas pelos resultados em relação aos principais estudos de born globals.

Adicionalmente a maioria dos dados coletados neste estudo foi baseada em percepções dos entrevistados. Apesar de os respondentes serem da alta direção das empresas e, portanto, serem naturalmente tratados como fontes confiáveis de dados, a opção pelo uso de respostas perceptuais acarreta um efeito inerente de viés. No entanto, devido ao tipo de empresa estudado, nascente e de pequeno porte, poderia ser restringida a proposta de pesquisas futuras que focassem em áreas mais específicas das EBTs (ex. marketing, $\mathrm{P} \& \mathrm{D}$, outras).

Estudos que coletem dados do ambiente institucional e testem com o fenômeno das EBTs born globals são bem vindos. Além disso, pouco ainda se sabe sobre o que acontece com a evolução e a sobrevivência das born globals, relativamente às empresas que entram no exterior tendo mais experiência no mercado doméstico. Assim, futuras pesquisas poderiam levantar perguntas, tais como: que proporção de born globals crescem e se tornam empresas bem-sucedidas? Qual a proporção das que se fundem ou são compradas por grandes empresas? Qual a taxa de mortalidade desse tipo de empresa? Quantas desistem de atuar no exterior? Enfim, trata-se de perguntas em aberto, em virtude da incipiente discussão da temática do empreendedorismo internacional. Sem dúvida, a pesquisa acadêmica no Brasil pode contribuir com essa área, pois, de um lado, existe uma vasta rede de pesquisadores de empreendedorismo e, de outro, há o crescimento de empreendedores que estão ultrapassando as fronteiras nacionais.

Artigo recebido em 10.05.2012. Aprovado em 17.10.2012.

\section{Referências}

Almor, T. (2000). Born global: the case of small and medium sized, knowledge-intensive, Israeli firms. In T. Almor, \& N. Hashai (Eds.), FDI, international trade and the economics of peacemaking (pp. 199-139). Rishon LeZion, Israel: The College of Management, Academic Studies Division.

Andersson, S. (2000). The internationalization of the firm from an entrepreneurial perspective. International Studies of Management \& Organization, 30(1), 63-92.

Associação Nacional de Entidades Promotoras de Empreendimentos Inovadores. (2011). Lista de sócios. Recuperado de http://www.anprotec.org.br/listaSimples2.php 
Autio, E., Sapienza, H., \& Arenius, P. (2005). International social capital, technology sharing, and foreign market learning in internationalizing entrepreneurial firms. In J. Katz \& D. Shepherd (Eds.), Advances in entrepreneurship, firm emergence and growth (Vol. 8, pp. 9-42). Oxford: Elsevier.

Bartlett, C. A., \& Ghoshal, S. (2000). Going global: lessons from late movers. Harvard Business Review, 78(2), 133-142.

Bell, J. (1995). The internationalization of small computer software firms: a further challenge to "stage" theories. European Journal of Marketing, 29(8), 60-75. doi: $10.1108 / 03090569510097556$

Bell, J., \& Mcnaughton, R. (2000, Julho). Born global firms: a challenge to public policy in support of internationalization. Marketing in a Global Economy Proceedings, Buenos Aires, Argentina. Recuperado ftp://ns1.ystp.ac.ir/YSTP/1/1/ROOT/DATA/PDF/ENTREPRENEURSHIP/039.PDF

Bloodgood, J., Sapienza, H., \& Almeida, J. (1996). The internationalization of new highpotential U.S. ventures: antecedents and outcomes. Entrepreneurship Theory and Practice, 20(4), 61-76.

Calantone, R., Kim, D., Schmidt, J., \& Cavusgil, S. T. (2006). The influence of internal and external firm factors on international product adaptation strategy and export performance: a threecountry comparison. Journal of Business Research, 59(2), 176-185. doi: 10.1016/j.jbusres.2005.05.001

Côrtes, M. R., Pinho, M., Fernandes, A. C., Smolka, R. B., \& Barreto, A. L. C. M. (2005). Cooperação em empresas de base tecnológica: uma primeira avaliação baseada numa pesquisa abrangente. São Paulo em Perspectiva, 19(1), 85-94. Recuperado em http://www.scielo.br/pdf/spp/v19n1/v19n1a07.pdf. doi: 10.1590/S0102-88392005000100007

Coutinho, L., Hiratuka, C., \& Sabatini, R. (2008). O investimento direto no exterior como alavanca dinamizadora da economia brasileira. In O. Barros \& F. Giambiagi (Orgs.), Brasil globalizado. (pp. 63-88) São Paulo: Campus.

Coviello, N., \& Munro, H. (1995) Growing the entrepreneurial firm: networking for international market development. European Journal of Marketing, 29(7), 49-61. doi: $10.1108 / 03090569510095008$

Crone, M. (2008, June). The emergence of dynamic smes in cluster context. Proceedings of the Celebration Conference on Entrepreneurship and Innovation - Organizations, Institutions, Systems and Regions, Copenhagen, CBS, Denmark, 25. Recuperado de http://www2.druid.dk/conferences/viewpaper.php?id=3727\&cf=29

Dib, L. A., \& Rocha, A. (2008, setembro). Internacionalização precoce versus internacionalização gradual: um estudo sobre born globals na indústria brasileira de software. Anais do Encontro Nacional da Associação Nacional de Pós-Graduação e Pesquisa em Administração, Rio de Janeiro, RJ, Brasil, 32.

Dib, L. A., Rocha, A., \& Silva, J. F. (2010). The internationalization process of Brazilian software firms and the born global phenomenon: examining firm, network, and entrepreneur variables. Journal of International Entrepreneurship, 8(3), 233-253. doi: 10.1007/s10843-010-0044-z

Dominguinhos, P. M., \& Simões, V. C. (2001). Portuguese born globals: an exploratory study. Anais do European International Business Academy, Paris, França, 26.

Fernandes, B. H. R., \& Seifert, R. E. J. (2007). Tipologia de novos empreendimentos globais. In A. C. C. Fleury \& M. T. L. Fleury (Orgs.), Internacionalização e os países emergentes (pp. 53-73). São Paulo: Atlas. 
Fernhaber, S. A., Gilbert, B. A., \& McDougall, P. P. (2003, June). International entrepreneurship and geographic clusters: an empirical examination of new venture internationalization. Proceedings of the Babson-Kauffman Entrepreneurship Research Conference, Wellesley, Massachusetts, United States.

Fernhaber, S. A., Gilbert, B. A., \& McDougall, P. P. (2008). International entrepreneurship and geographic location: an empirical examination of new venture internationalization. Journal of International Business Studies, 39(2), 267-290. doi: 10.1057/palgrave.jibs.8400342

Fernhaber, S. A., McDougall, P. P, \& Oviatt, B. (2007). Exploring the role of industry structure in new venture internationalization. Entrepreneurship Theory and Practice, 31(4), 517-542. doi: 10.1111/j.1540-6520.2007.00186.x

Furman, J. L., \& Heyes, R. (2004). Catching up or standing still? National innovative productivity among 'follower' countries, 1978-1999. Research Policy, 33(9), 1329-1354. doi: 10.1016/j.respol.2004.09.006

Gabrielsson, M., \& Kirpalani, V. H. M. (2004). Born globals: how to reach new business space rapidly. International Business Review, 13(5), 555-571. doi: 10.1016/j.ibusrev.2004.03.005

Gabrielsson, M., Kirpalani, V. H. M., Dimitratos, P., Solberg, C. A., \& Zucchellag, A. (2008). Born globals: propositions to help advance the theory. International Business Review, 17(4), 385-401. doi: 10.1016/j.ibusrev.2008.02.015

Govindarajan, V., \& Ramamurti, R. (2011). Reverse innovation, emerging markets, and global strategy. Global Strategy Journal, 1(3/4), 191-205. doi: 10.1111/j.2042-5805.2011.00023.x

Guillén, M., \& García-Canal, E. (2009). The American model of the multinational firm and the "new" multinationals from emerging economies. Academy of Management Perspectives, 23(2), 23-35.

Hair, J. F., Black, W. C., Anderson, R. E., \& Tatham, R. L. (2005). Análise multivariada de dados (5a ed.). Porto Alegre: Bookman.

Hair, J., Black, W., Babin, B., Andersson, R., \& Tatham, R. (2006). Análise multivariada de dados (6a ed.). Porto Alegre: Bookman.

Holtbrugge, D., \& Wessely, B. (2009). Initiating forces and success factors of born global firms. European Journal of International Management, 3(2), 232-260. doi: 10.1504/EJIM.2009.024324

Knight, G. A., \& Cavusgil, S. (1996). The born global firm: a challenge to traditional internationalization theory. In S. Cavusgil \& T. Madsen (Orgs.), Advances in international marketing (pp. 11-26). Greenwich, CT: JAI Press.

Knight, G. A., \& Cavusgil, S. T. (2004). Innovation, organizational capabilities, and the born-global firm. Journal of International Business Studies, 35(2), 124-141. doi: 10.1057/palgrave.jibs. 8400071

Knight, G. A., \& Kim, D. (2009). International business competence and the contemporary firm. Journal of International Business Studies, 40(2), 255-273. doi: 10.1057/palgrave.jibs.8400397

Loane, S., \& Bell, J. (2006). Rapid internationalization among entrepreneurial firms in Australia, Canada, Ireland and New Zealand. International Marketing Review, 23(5), 467-485. doi: $10.1108 / 02651330610703409$

Luostarinen, R., \& Gabrielsson, M. (2006). Globalization and maketing strategies of born globals in SMOPECs. Thunderbird International Business Review, 48(6), 773-801. doi: 10.1002/tie.20122. 
Madsen, T. K., \& Servais, P. (1997). The internationalization of born globals - an evolutionary process? International Business Review, 6(6), 561-583. doi: 10.1016/S0969-5931(97)00032-2

Maroco, J. (2010). Análise de equações estruturais: fundamentos teóricos, software \& aplicações. Portugal, Lisboa: Editora ReportNumber.

Mathews, J. A. (2006). Dragon multinationals: new players in 21st century globalization. Asia Pacific Journal of Management, 23(1), 5-27. doi: 10.1007/s10490-006-7161-1

Mathews, J., \& Zander, I. (2007). The international entrepreneurial dynamics of accelerated internationalisation. Journal of International Business Studies, 38(3), 387-403. doi: 10.1057/palgrave.jibs.8400271

Mcdougall, P., \& Oviatt, B. M. (1996). New venture internationalization, strategic change, and performance: a follow-up study. Journal of Business Venturing, 11(1), 23-40. doi: 10.1016/0883-9026(95)00081-X

Moen, O. (2002). The born globals: a new generation of small European exporters. International Marketing Review, 19(2), 156-175. doi: 10.1108/02651330210425015

Nemes, S., Jonasson, J. M., Genell, A., \& Steineck, G. (2009). Bias in odds ratios by logistic regression modelling and sample size. BMC Medical Research Methodology, 9(56), 1-5. doi: $10.1186 / 1471-2288-9-56$

Organização para a Cooperação e o Desenvolvimento Econômico. (2003). The measurement of scientific and technical activities: proposed standard practice for surveys of research and experimental development - Frascati Manual (5th ed.). Paris: Author.

Oviatt, B. M., \& McDougall, P. P. (1994). Toward a theory of international new ventures. Journal of International Business Studies, 25(1), 45-64. doi: 10.1057/palgrave.jibs.8400128.

Oviatt, B. M., \& McDougall, P. P. (1995). Global start-ups: entrepreneurs on a worldwide stage. Academy of Management Executive, 9(2), 30-43. doi: 10.5465/AME.1995.9506273269

Pinho, M. (Coord.). (2005). Empresas de base tecnológica - Diretório da pesquisa privada (Relatório de Pesquisa). São Carlos, SP, Universidade Federal de São Carlos.

Reddy, P. (2011). Global innovation in emerging economies. New York: Routledge

Rialp, A. C., Rialp, J. C., \& Knight, G. A. (2005). The phenomenon early internationalizing firms: what do we know after a decade (1993-2003) of scientific inquiry? International Business Review, 14(2), 147-166. doi: 10.1016/j.ibusrev.2004.04.006

Ribeiro, F. C. F., \& Pimentel, J. A. (2009, setembro). Empresas born globals brasileiras: a influência do perfil do empreendedor e da localização geográfica. Anais do Encontro Nacional da Associação Nacional de Pós-Graduação e Pesquisa em Administração, São Paulo, SP, Brasil, 33.

Roberts, E., \& Senturia, T. (1996). Globalizing the emerging high-technology company. Industrial Marketing Management, 25(6), 491-506. doi: 10.1016/S0019-8501(96)00072-7

Rodrigues, D. A., \& Almeida, L. S. T. (Coords.). (2008). Competitividade da indústria paulista: propostas de políticas. São Paulo: Instituto de Pesquisas Tecnológicas do Estado de São Paulo. Recuperado http://www.desenvolvimento.sp.gov.br/noticias/files/livro_competitividade2009_baixa.pdf

Santos, D. T., \& Pinho, M. (2010). Análise do crescimento das empresas de base tecnológica no Brasil. Produção, 20(2), 214-223. 
Simões, V., \& Dominguinhos, P. (2001, December). Portuguese born globals: an exploratory study. Proceedings of the European International Business Academy - EIBA Annual Conference, Paris, França, 27.

Sperling, G. (2005). Product, operation and market. strategies of technology-intensive born globals the case of Israeli telecommunication born globals. Helsinki School of Economics. Recuperado de http://hsepubl.lib.hse.fi/pdf/diss/a255.pdf

Toledo, J. C., Silva, S. L., Mendes, G. H. S., \& Jugend, D. (2008). Fatores críticos de sucesso no gerenciamento de projetos de desenvolvimento de produto em empresas de base tecnológica de pequeno e médio porte. Gestão \& Produção, 15(1), 117-134. doi: 10.1590/S0104530X2008000100011

Vapola, T. J., Tossavainen, P., \& Gabrielsson, M. (2008). The battleship strategy: the complementing role of born globals in MNC's new opportunity creation. Journal of International Entrepreneurship, 6(1), 1-21. doi: 10.1007/s10843-007-0018-y

Vittinghoff, E., Sen, S., \& McCulloch, C. E. (2009). Sample size calculations for evaluating mediation. Statistics in Medicine, 28(4), 541-557. doi: 10.1002/sim.3491

Zahra, S., \& George, G. (2002). International entrepreneurship: the current status of the field and future research agenda. In M. Hitt, R. Ireland, M. Camp, \& D. Sexton (Eds.), Strategic leadership: creating a new mindset (pp. 255-288). London, UK: Blackwell, 255-288.

Zucchella, A. (2002, December). Born global versus gradually internationalizing firms: an analysis based on the italian case. Proceedings of the European International Business Academy, Atenas, Grécia, 28. 